\title{
Galectin-1-Mediated Apoptosis in Mycosis Fungoides: The Roles of CD7 and Cell Surface Glycosylation
}

Alice A. Roberts, M.D., Ph.D., Maho Amano, Ph.D., Christopher Felten, M.D., Marisa Galvan, Ph.D., Giri Sulur, Ph.D., Lauren Pinter-Brown, M.D., Udo Dobbeling, Ph.D., Gunter Burg, M.D., Jonathan Said, M.D., Linda G. Baum, M.D., Ph.D.

Departments of Pathology (AAR, MA, CF, MG, GS, JS, LGB) and Medicine (LP-B) and the Jonsson Comprehensive Cancer Center (JS, LGB), UCLA School of Medicine, Los Angeles, California; and Department of Dermatology, University of Zurich Medical School, Zurich, Switzerland (UD, GB)

Sezary cells, the malignant $T$ cells in mycosis fungoides/Sezary syndrome, resist a variety of apoptosis-inducing agents, a feature that contributes to the poor response to therapy in mycosis fungoides. Galectin-1 is a mammalian lectin that triggers $T$ cell apoptosis. For $T$ cells to be susceptible to galectin-1-induced apoptosis, the $T$ cells must express specific glycoprotein receptors, such as $\mathrm{CD} 7$, that bear the specific oligosaccharides recognized by galectin-1. Because Sezary cells are characteristically $\mathrm{CD}^{-}$, lack of $\mathrm{CD} 7$ expression has been proposed to render Sezary cells resistant to galectin1-induced death. However, the role played by aberrant cell surface glycosylation in resistance of Sezary cells to galectin-1 has not been examined. In this study, we demonstrated abundant galectin-1 in mycosis fungoides skin lesions, indicating that Sezary cells are exposed to galectin-1 in vivo. To determine specific characteristics of Sezary cells that contribute to galectin-1 resistance, we assessed $\mathrm{CD} 7 \mathrm{ex}$ pression and cell surface glycosylation of Sezary cells in mycosis fungoides lesions and of four Sezary $\mathrm{T}$ cell lines. Sezary cells in primary lesions and Sezary $\mathbf{T}$ cell lines demonstrated a characteristic "glycotype" with sialylated core 10 -glycans that promote galectin-1 resistance. Expression of $\mathrm{CD} 7$ was necessary but not sufficient for galectin-1-induced death of Sezary cell lines. In addition, $\mathrm{CD}^{-}$Sezary cell lines, and Sezary cells within mycosis fungoides lesions, expressed galectin-1, whereas CD7-positive

Copyright () 2003 by The United States and Canadian Academy of Pathology, Inc.

VOL. 16, NO. 6, P. 543, 2003 Printed in the U.S.A

Date of acceptance: March 1, 2003.

Authors AAR and MA contributed equally to this paper.

This work was supported by grants from the Lymphoma Research Foun-

dation (MA, MG, and JS) and by NIH GM63281 (LGB) and NIH CA66533 (JS).

Address reprint requests to: Linda G. Baum, M.D., Ph.D., Department of Pathology, UCLA School of Medicine, 10833 Le Conte Ave., Los Angeles, CA 90095-1732; fax: 310-206-0657; e-mail: lbaum@mednet.ucla.edu.

DOI: 10.1097/01.MP.0000071840.84469.06
Sezary cell lines did not express galectin-1. We propose that both loss of CD7 expression and altered cellular glycosylation contribute to apoptosis resistance of malignant $\mathrm{T}$ cells in mycosis fungoides.

KEY WORDS: Apoptosis, CD7, Galectin, Glycosylation, Mycosis fungoides.

Mod Pathol 2003;16(6):543-551

Mycosis fungoides is the most common of primary cutaneous lymphomas (1-3). Early mycosis fungoides skin lesions present as erythematous patches that may progress to raised plaques or tumors $(2,4)$. As shown in Figure 1, mycosis fungoides tumor cells, or Sezary cells, are epidermotropic, small to medium-sized lymphocytes that are typically $\mathrm{CD}^{+}$and $\mathrm{CD}^{-}$(4-6).

Although early (patch stage) mycosis fungoides often follows an indolent course, approximately one quarter of patients with generalized disease progress to a more advanced clinical stage, and $\geq 20 \%$ of these patients eventually die of the disease $(7,8)$. Mycosis fungoides may also undergo transformation to cutaneous large T-cell lymphoma or present in a leukemic form termed Sezary syndrome, both of which have a grave prognosis $(5,7)$. Because a significant proportion of patients with mycosis fungoides undergo clinical progression associated with a high mortality, it may be important to initiate treatment early in the course of the disease.

Chemotherapeutic and radiation-based treatments have been moderately effective in early cases of mycosis fungoides; however, the disease often recurs, and these treatment approaches have limited efficacy in more advanced stages or systemic disease $(9,10)$. Resistance to multiple chemotherapeutic agents has been attributed to a decreased sensitivity of Sezary cells to apoptosis (10-12). Sezary cells have been directly shown to be resistant to exogenous apoptotic agents such as dexametha- 

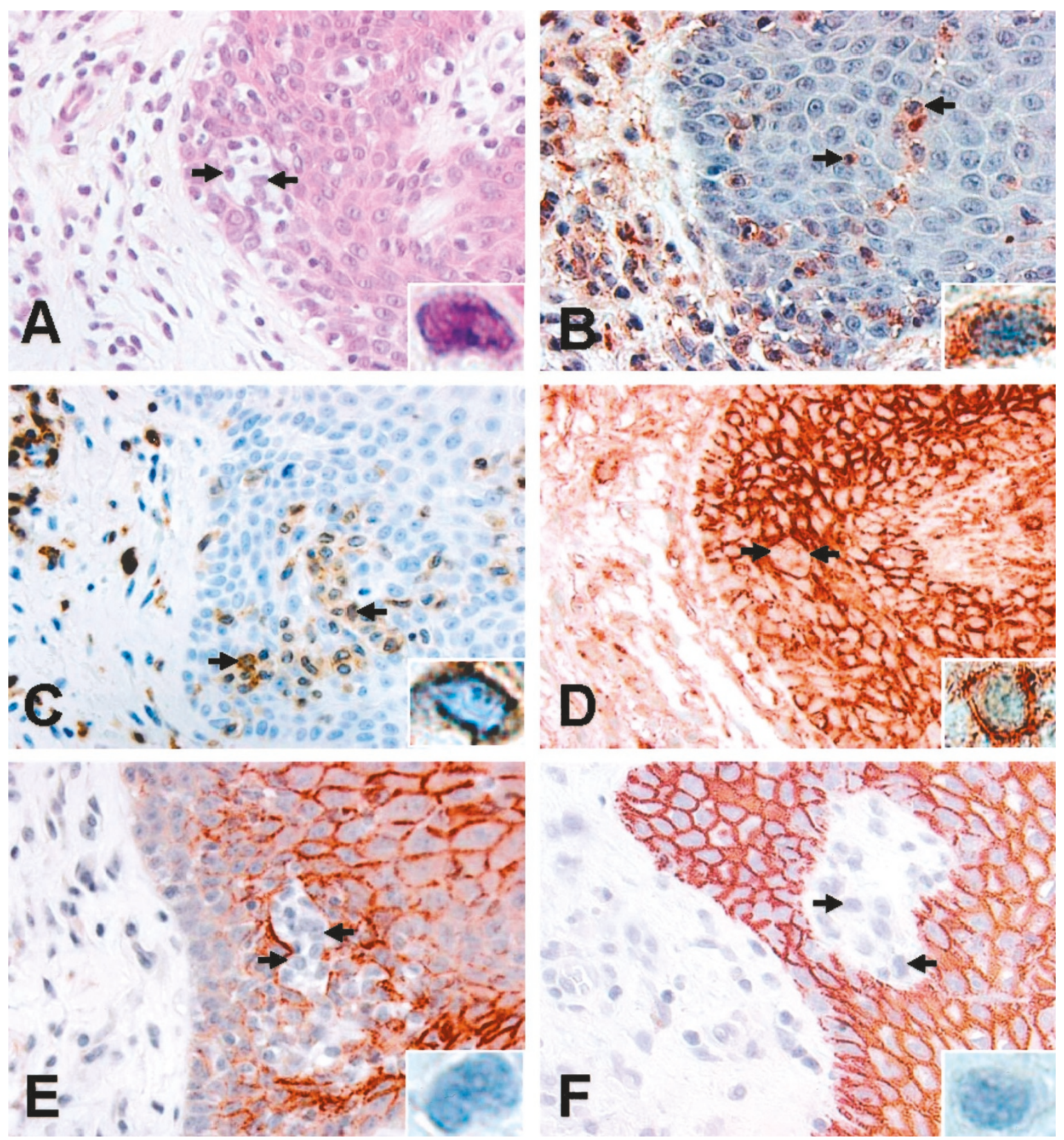

FIGURE 1. Glycophenotype of mycosis fungoides lesions. A, representative patch stage mycosis fungoides lesion with Sezary cells (arrows in all panels) infiltrating epidermis and dermis (H\&E stain; for all panels, 400×; inset, 1000×). B, expression of galectin-1 in mycosis fungoides lesions. Galectin-1 immunoreactivity is visible in the dermis, and galectin-1 ${ }^{+}$cells are infiltrating the epidermis. Cytoplasmic immunoreactivity of Sezary cell within the epidermis (inset) demonstrates abundant expression of galectin-1. C, CD3 immunostaining demonstrates numerous Sezary cells infiltrating the epidermis. D-F show glycosylation patterns visualized by lectin histochemistry. D, PHA reacts with branched $N$-glycans. Sezary cells are strongly $\mathrm{PHA}^{+}$, as are surrounding keratinocytes. E, SNA reacts with terminal sialic acid residues in $\alpha 2,6$ linkage, primarily on $N$-glycans. Absent SNA reactivity of Sezary cells contrasts with strong SNA reactivity of keratinocytes. F, PNA reacts with non-sialylated O-glycans. Absent PNA reactivity of Sezary cells contrasts with strong PNA reactivity of keratinocytes.

sone and retinoic acid when cultured in the presence of interleukin-15, a cytokine produced by both Sezary cells and keratinocytes (13). Furthermore, the number of apoptotic tumor cells within mycosis fungoides lesions is reduced in advanced disease compared with in early disease (14), suggesting that Sezary cells also develop increased resistance to endogenous inducers of apoptosis with disease progression.

Physiologic triggers of apoptosis in the skin include the galectins, a family of mammalian lectins or carbohydrate-binding proteins that bind to cell surface glycoproteins or glycolipids and regulate cell growth, cell adhesion, and cell death (see 15-18 for review). Different galectins can be either pro- or anti-apoptotic (19-30). Galectin-1 induces Fasindependent death of $\mathrm{T}$ cells, as well as prostate and breast cancer cells (19-24). Galectin-7 is also pro-apoptotic (25), and galectin-7 overexpression has been implicated in apoptosis of sun-damaged keratinocytes (26). Several galectins, including galectins 1 and 7 , have been identified in skin (26, 
31-35), implying that Sezary cells may acquire resistance to endogenous pro-apoptotic galectins.

Sezary cells are typically CD7 ${ }^{-}$. CD7 is a T-cell surface glycoprotein that binds galectin-1 and is essential for galectin-1-mediated T-cell death (36, 37 ). In addition to the CD7 polypeptide, galectin-1mediated $\mathrm{T}$-cell apoptosis requires the expression of specific saccharide ligands that are present on a subset of glycoprotein receptors, including CD7 (36). A recent report examined a panel of Sezary cell lines and correlated lack of CD7 expression with resistance to galectin-1-induced apoptosis (38). However, tumor cells are known to have aberrant patterns of cell surface glycosylation, a feature that contributes to the malignant phenotype (39). This suggests that absence of CD7 on Sezary cells and altered cell surface glycosylation could both confer resistance to galectin-1-mediated apoptosis. In the present study, we characterized the expression pattern of saccharides and glycoprotein receptors recognized by galectin-1 on Sezary cells in primary mycosis fungoides skin lesions and on established Sezary cell lines. Using Sezary cell lines, we examined the relationship between CD7 expression, cell surface glycosylation, and susceptibility to galectin-1 death.

\section{MATERIALS AND METHODS}

\section{Reagents}

The Hut78, HH, and CEM cell lines were obtained from the American Type Culture Collection (Gaithersburg, MD). The MyLa 2059 (mycosis fungoides) and SeAx (Sezary syndrome) cell lines were the kind gift of Dr. Keld Kaltof, University of Aarhus, Denmark, as previously described (13). The SeAx/i designation refers to the SeAx cells grown in the absence of exogenous interleukins added to the culture, as described in (13). Cell cultures were maintained in RPMI 1640 medium (Life Technologies, Gaithersburg, MD), with $10 \%$ fetal bovine serum and 10 mM HEPES (complete media). Human recombinant galectin-1 was prepared as described previously (20) and was used for preparation of a rabbit polyclonal galectin-1 antiserum. Lectins, antibodies, and other reagents used in the study were as follows: Sambucus nigra agglutinin (SNA)-biotin, phytohemagglutinin (PHA)-biotin (EY Laboratories, San Mateo, CA); peanut agglutinin (PNA)-biotin (Roche-Boehringer Manheim, Germany); LT-7 (CD7; Advanced Immunochemical, Long Beach, CA); MT310 (CD4); DK25 (CD8), mouse IgG1 and IgG2a negative controls, fluorescein isothiocyanate (FITC)conjugated goat anti-mouse Ig, and horseradish peroxidase (HRP)-conjugated goat anti-rabbit Ig (DAKO, Carpinteria, CA); FITC-conjugated streptavidin (Jackson Immunoresearch Laboratories, West Grove, PA); annexin V, 7-aminoactinomycin D (Molecular Probes, Eugene, OR); Vibrio cholerae neuraminidase and bovine serum albumin (BSA; Sigma-Aldrich, St. Louis, MO); Hanks Balanced Salt Solution (Gibco, Carlsbad, CA); and Enhanced Chemiluminescence Detection Kit (Amersham, Piscataway, NJ). Biotinylated BSA was prepared using the EZ-Link sulfo-NHS-biotin reagent (Pierce, Rockford, IL) according to the manufacturer's directions.

\section{Mycosis Fungoides Biopsy Selection}

Archival tissue from 15 mycosis fungoides biopsy specimens from the Surgical Pathology Division of the Department of Pathology and Laboratory Medicine at UCLA were examined, including 6 patchstage, 6 plaque-stage, and 3 tumor-stage lesions. All cases were documented as $\mathrm{CD} 4^{+}$and $\mathrm{CD} 7^{-}$by immunohistochemistry at the time of diagnosis.

\section{Immunohistochemistry and Lectin Staining}

Three- to five-micrometer sections of formalinfixed skin biopsies were stained as previously described $(40,41)$, using primary antiserum or lectins at the following dilutions: rabbit antigalectin-1 (1/1000); biotinylated-PHA (1/100); biotinylated-PNA (1/40); and biotinylated-SNA $(1 / 40)$. To detect bound antibody or lectins, slides were incubated with goat anti-rabbit Ig-HRP (1/ 1000) or streptavidin-HRP (1/200) for 30 minutes or 2 hours, respectively, at room temperature. After washing, slides were developed with AEC.

\section{Phenotypic Analysis}

Either with $0.2 \mu \mathrm{g}$ of the indicated antibody or with $0.5 \mu \mathrm{g}$ of biotinylated lectin in a final volume of $100 \mu \mathrm{L}, 10^{5}$ cells of the indicated cell lines were incubated for 45 minutes at $4^{\circ} \mathrm{C}$, followed by FITCconjugated secondary antibody or FITC-conjugated streptavidin, respectively, for 45 minutes at $4^{\circ} \mathrm{C}$. Controls were equivalent amounts of IgG1 or IgG2a for the relevant antibodies, or $0.5 \mu \mathrm{g}$ of biotinylated BSA for the lectins. Flow cytometry data was acquired and analyzed using Becton Dickinson FACScan and CELLQuest software. For analysis after neuraminidase treatment, cells were first incubated with $25 \mathrm{mU}$ of $V$. cholerae neuraminidase in Hanks balanced salt solution, or in buffer alone, for $2 \mathrm{hrs}$ at $37^{\circ} \mathrm{C}$, then washed and analyzed as above.

\section{Cell Death Assays}

Galectin-1 death assays were performed essentially as previously described $(20,42)$. Briefly, $10^{5}$ cells of the indicated cell lines were incubated with $20 \mu \mathrm{M}$ of galectin-1 in $200 \mu \mathrm{L}$ of media containing $1.0 \mathrm{~mm}$ dithiothreitol (DTT), or in media with DTT 
alone as control, for 6 hours at $37^{\circ} \mathrm{C}$ in $5 \% \mathrm{CO}_{2}$. Cells were analyzed on a Becton Dickinson FACScan. Cell death was assessed by annexin V binding and propidium iodide permeability, using CELLQuest software. Percentage cell death was determined as follows: $100-\left[\left(\%\right.\right.$ annexinV ${ }^{-}$propidium iodide $^{-}$(galectin-1)/\% annexinV ${ }^{-}$propidium iodide ${ }^{-}$(control)]. Statistical analysis was done by analysis of variance, and posthoc analysis, by the Newman-Keuls multiple comparison test using Prism 3.0 software by Graphpad.

\section{Immunoblotting}

Immunoblotting for galectin-1 expression by the indicated cell lines was performed with rabbit antihuman galectin-1 polyclonal antiserum $(1: 10,000)$. Purified recombinant galectin- 1 and the $\theta-35$ thymic stromal cell line (gift of Dr. Ken Dorshkind, UCLA School of Medicine) were used as positive controls. Bound antibody was detected with goat anti-rabbit IgG-HRP (1:5000). Immunoblots were developed for 1 minute by the Enhanced ChemiLuminescence method according to the manufacturer's directions and immediately were exposed for 30 seconds to 1 minute.

\section{RESULTS}

\section{Galectin-1 Immunoreactivity in Mycosis Fungoides Biopsies}

We examined galectin- 1 expression in 15 mycosis fungoides skin lesions. In all cases of patch and tumor stage lesions, galectin-1 was present within both dermis and epidermis in close proximity to infiltrating lymphocytes and Sezary cells (Fig. 1B). There was strong galectin-1 reactivity on the surface of infiltrating Sezary cells and lymphocytes in the epidermis and dermis, compared with the background of predominantly negative keratinocytes. In addition, the galectin-1 immunoreactivity in the cytoplasm of some Sezary cells (inset, Fig. 1B) suggested that the tumor cells synthesized galectin-1, as well as being exposed to abundant galectin-1 in the extracellular milieu. In the dermis, there were also scattered galectin- $1^{+}$non-neoplastic cells, including fibroblasts, endothelial cells, and macrophages, as previously described $(34,35)$.

\section{Glycosylation Patterns in Mycosis \\ Fungoides Lesions}

Galectin-1 binds to specific saccharide ligands on $\mathrm{T}$-cell glycoproteins to trigger cell death (37). These saccharide structures can be detected by reactivity with specific plant lectins (41-45). As susceptibility to galectin- 1 is regulated by expression of these saccharide ligands, it was important to characterize the saccharide structures on Sezary cells.

Galectin-1 preferentially binds poly- $N$-acetyllactosamine (poly-LacNAc)-containing saccharides on T-cell surface glycoproteins (42). Poly-LacNAc sequences can be found on branched $N$-glycans that also bind the plant lectin phytohemagglutinin (PHA; 42, 46). To determine whether Sezary cells expressed poly-LacNAc sequences, we examined the cells for reactivity with PHA. In all samples, strong PHA reactivity was seen on the surface of both Sezary cells and small, round lymphocytes within the dermis and epidermis (Fig. 1D). This was consistent with prior reports of Sezary cells bearing the branched $N$-glycans recognized by PHA $(47,48)$. Strong PHA reactivity was also seen on other cells within the dermis and epidermis.

The plant lectin PNA detects unsialylated core 1 O-glycans on cell surface glycoproteins. Sialylation of O-glycans by the ST3Gal I enzyme blocks PNA binding and also prevents the addition of polyLacNAc sequences to form core 2 O-glycans that bind galectin- 1 and are required for galectin-1-induced T-cell death $(41,42,49)$. For non-neoplastic human thymocytes and T cells, the ability to bind PNA correlates with susceptibility to galectin-1-induced death $(20,21)$. In all samples, there was no detectable staining of Sezary cells with PNA (Fig. $1 F)$. The $\mathrm{PNA}^{-}$Sezary cells contrast with the $\mathrm{PNA}^{+}$ keratinocytes and with scattered small PNA+ lymphocytes observed within the dermis and epidermis. The small $\mathrm{PNA}^{+}$lymphocytes in the dermis were concentrated in perivascular areas (data not shown) and are likely reactive, non-neoplastic lymphocytes that bind high levels of PNA (50).

The plant lectin Sambucus nigra agglutinin (SNA) detects $\alpha$-2,6-linked sialic acid residues on cell surface glycoproteins (45). The presence of a terminal $\alpha$-2,6-linked sialic acid can mask the LacNAc sequences that are preferred galectin-1 ligands (37, 51), and SNA reactivity of medullary thymocytes and T-cell lines correlates with loss of susceptibility to galectin-1 $(43,45)$. In all samples, no SNA reactivity was detected on infiltrating Sezary cells or on small round lymphocytes present in the dermis and epidermis (Fig. 1E). The SNA ${ }^{-}$Sezary cells contrasted with strongly $\mathrm{SNA}^{+}$maturing epidermal keratinocytes.

In summary, lectin histochemistry of Sezary cells in mycosis fungoides lesions demonstrated that the malignant cells were $\mathrm{PHA}^{+}$and $\mathrm{SNA}^{-}$. Although this glycophenotype correlates with the phenotype of nonneoplastic $\mathrm{T}$ cells that are susceptible to galectin-1, the Sezary cells in the lesions were also $\mathrm{PNA}^{-}$, indicating that the Sezary cells bear core 1 O-glycans capped with sialic acid. The presence of sialylated core 1 O-glycans on Sezary cells would 
reduce susceptibility of these cells to death triggered by galectin-1 present in skin $(42,49)$.

\section{Cell Surface Phenotype of Sezary Cell Lines}

The abundant galectin-1 immunoreactivity that we observed in mycosis fungoides biopsies (Fig. 1B) indicates that Sezary cells are exposed to galectin-1 in vivo. We hypothesized that Sezary cells may resist galectin-1-mediated apoptosis either because the malignant cells do not express CD7 that is essential for galectin-1-mediated apoptosis (36) or because PNA ${ }^{-}$Sezary cells have aberrant cell surface glycosylation that contributes to decreased galectin-1 sensitivity. To examine the relationship between CD7 expression, cell surface glycosylation, and susceptibility to galectin-1, we analyzed cell surface glycosylation and CD7 expression of four Sezary cell lines, Hut78, MyLa 2059, HH, and SeAx/i. As a control, we analyzed a subclone of the CEM T-lymphoblastoid cell line that we have previously demonstrated is highly susceptible to galectin-1 (37). As shown in Figure 2, CD7 surface expression differed significantly among the five cell lines. $\mathrm{HH}$ and SeAx/i cells exhibited high levels of CD7 expression, comparable to that of CEM cells. In contrast, the Hut78 and MyLa 2059 cells were $\mathrm{CD}^{-}$. Hut78 and MyLa 2059 cells also had lower surface levels of CD4 than $\mathrm{HH}$ and SeAx/i cells, although we have previously found that $\mathrm{CD} 4$ ex-

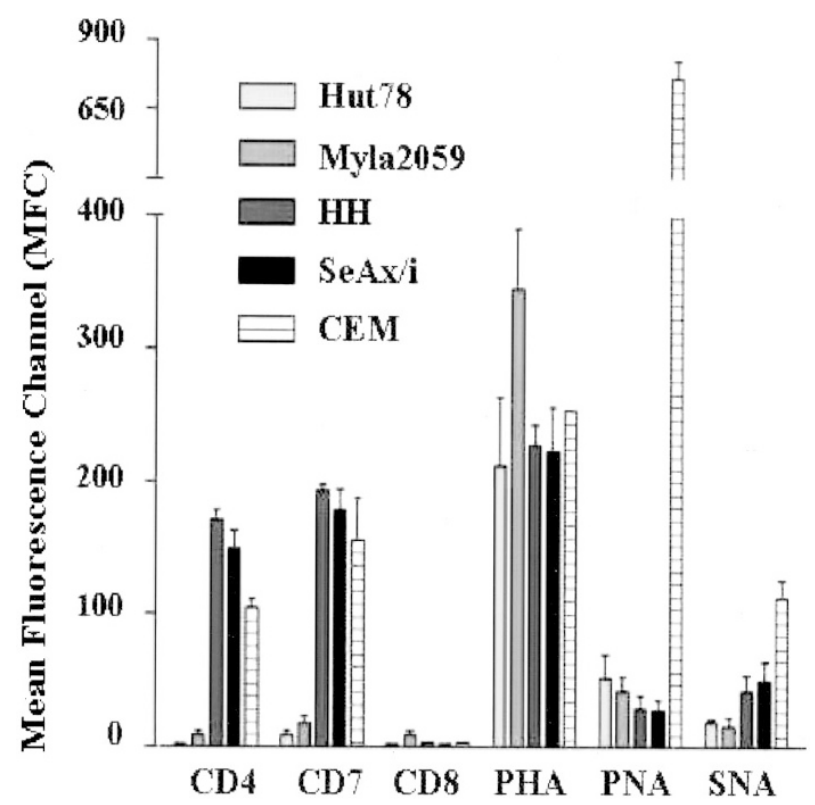

FIGURE 2. Cell surface phenotype of Sezary cell lines. The Hut78, MyLa 2059, HH, and SeAx/i cells are Sezary cell lines. The CEM cell line was derived from a T-acute lymphoblastic leukemia. The vertical axis indicates the mean fluorescence channel (MFC) detected by flow cytometry with the indicated lectin or antibody. For lectin flow cytometry, negative controls were incubated with biotinylated bovine serum albumin. MFC of the cell lines with biotin-BSA was $\leq 4$ for the Hut78, HH, and SeAx/i cells and $\leq 15$ for Myla2059 and CEM cell lines. Results are mean \pm SE of three experiments, each done in triplicate. pression is not required for galectin-1 susceptibility (37). None of the cell lines expressed detectable cell surface CD8.

Despite differences in CD7 expression, the four Sezary cell lines had similar cell surface glycosylation profiles. All four cell lines strongly bound PHA. There was very dim staining of Hut78 and MyLa 2059 with PNA (background mean fluorescence channels 4 and 15, respectively), whereas no binding of PNA over background was observed for $\mathrm{HH}$ and SeAx/i cells. There was very dim staining of $\mathrm{HH}$ and SeAx/i with SNA (background mean fluorescent channels 3 and 2, respectively), whereas no binding of SNA over background was observed for Hut78 and MyLa 2059 cells. Thus, all four cell lines demonstrated a lectin-binding profile, i.e., $\mathrm{PHA}^{+}$, $\mathrm{PNA}^{-/ l o w}$, and $\mathrm{SNA}^{-/ \mathrm{low}}$, identical to that observed for Sezary cells in primary mycosis fungoides skin lesions (Fig. 1), indicating that the four Sezary cell lines are phenotypically similar to primary Sezary cells with regard to cell surface glycosylation. However, in contrast to the minimal to absent PNA reactivity of the four Sezary cell lines, the galectin1-sensitive CEM $\mathrm{T}$ cell line was strongly $\mathrm{PNA}^{+}$, demonstrating the presence of non-sialylated O-glycans on the CEM cells.

\section{Galectin-1-Mediated Apoptosis of Sezary Cell Lines}

To examine the role of CD7 in galectin-1-mediated cell death, we determined the susceptibility of the Sezary cell lines to galectin-1. Significantly, all four Sezary cell lines bound galectin-1, as demonstrated by cell agglutination (data not shown), because other galectin-1 receptors, e.g., CD45, are also expressed by these cells. As shown in Figure 3, the $\mathrm{CD}^{-}$Sezary cell lines Hut78 and MyLa 2059 demonstrated essentially no galectin-1-induced cell death $(<1 \%)$. In contrast, we observed a modest but reproducible and statistically significantly higher level of galectin- 1 cell death for the $\mathrm{CD}^{+}{ }^{+} \mathrm{HH}$ cell line compared with the case of the $\mathrm{CD} 7^{-}$Hut78 and MyLa 2059 cells $(P<.05)$. However, CD7 expression alone was not sufficient for galectin-1-induced death, because SeAx/i cells had a significantly lower level of galectin-1-induced cell death than did $\mathrm{HH}$ cells $(P<.05)$, despite similar levels of CD7 expression on the $\mathrm{HH}$ and SeAx/i cell lines (Fig. 2). CEM T cells, which express CD7 at a level comparable to that seen on $\mathrm{HH}$ and SeAx/i, were very sensitive to galectin-1-induced death, as previously reported, so the reduced susceptibility of $\mathrm{HH}$ cells and the resistance of SeAx/i cells to galectin-1 cannot solely be attributed to insufficient expression of $\mathrm{CD} 7$ by the Sezary cell lines. 


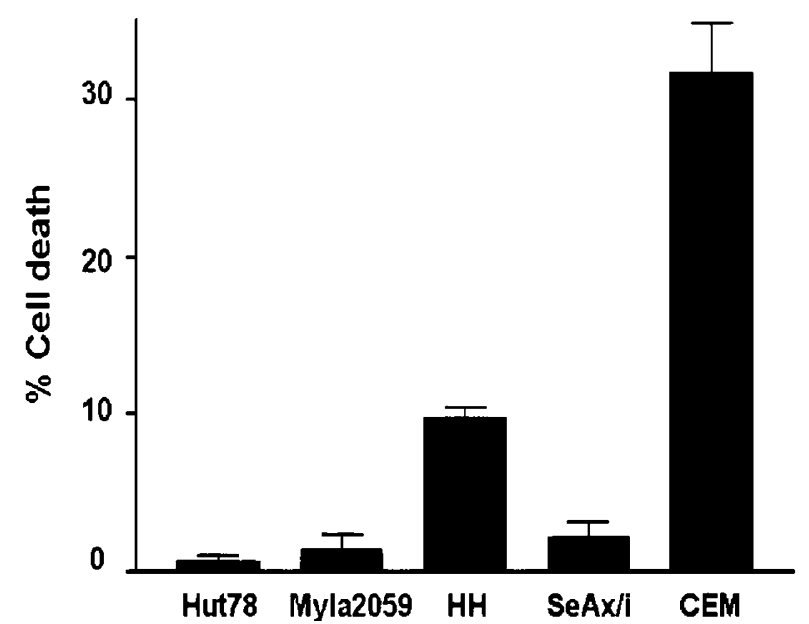

FIGURE 3. Galectin-1-induced cell death of Sezary cell lines. Cell death was measured by annexin $\mathrm{V}$ binding and propidium iodide permeability as described in Materials and Methods. No appreciable death of the CD7 ${ }^{-}$Hut78 and MyLa 2059 cell lines was observed. The $\mathrm{CD}^{+} \mathrm{HH}$ cell line was modestly susceptible to galectin-1 death $(P<$ .05 , compared with $\mathrm{CD}^{-}$lines), whereas the $\mathrm{CD}^{+}$cell line SeAx/i was not susceptible to galectin-1-induced death. Results are mean \pm SE of three experiments, each done in triplicate.

\section{Sialylated O-Glycans on Sezary Cells}

The absence of PNA reactivity of Sezary cells in skin lesions and of Sezary cell lines suggested that O-glycans on these cells may be masked by terminal sialic acids. Low PNA binding and sialylated core $1 \mathrm{O}$-glycans are found on naïve and memory $\mathrm{T}$ cells that are resistant to galectin-1, but not on activated effector $\mathrm{T}$ cells (50) that are susceptible to galectin-1. This is likely due to competition for acceptor substrate between the ST3Gal I sialyltransferase and the core $2 \beta$-1,6- $N$-acetylglycosaminyltransferase (core $2 \mathrm{GnT}$ ) enzyme that creates saccharide ligands required for galectin-1 death $(42,49)$. To determine whether sialylated core 1 O-glycans were present on the Sezary cells, cells were treated with $V$. cholerae neuraminidase to remove sialic acid from cell surface glycoproteins. Neuraminidase treatment dramatically increased PNA binding of all four Sezary cell lines, to levels comparable to that for the CEM cell line (Fig. 4). Although removal of sialic acid by neuraminidase increased PNA binding, this treatment did not increase susceptibility to galectin-1 cell death (data not shown). This was not surprising; de-sialylated cell surface glycoproteins would still lack core 2 $\mathrm{O}$-glycans, as these structures are added to nascent glycoproteins during synthesis in the Golgi. Thus, sialylation of core 1 O-glycans on Sezary cells may inhibit core $2 \mathrm{O}$-glycan addition to cell surface glycoproteins and contribute to resistance to galectin-1 death.

\section{Synthesis of Galectin-1 by Sezary Cells}

As shown in Figure 1B, immunoreactive galectin-1 was detected within the cytoplasm of
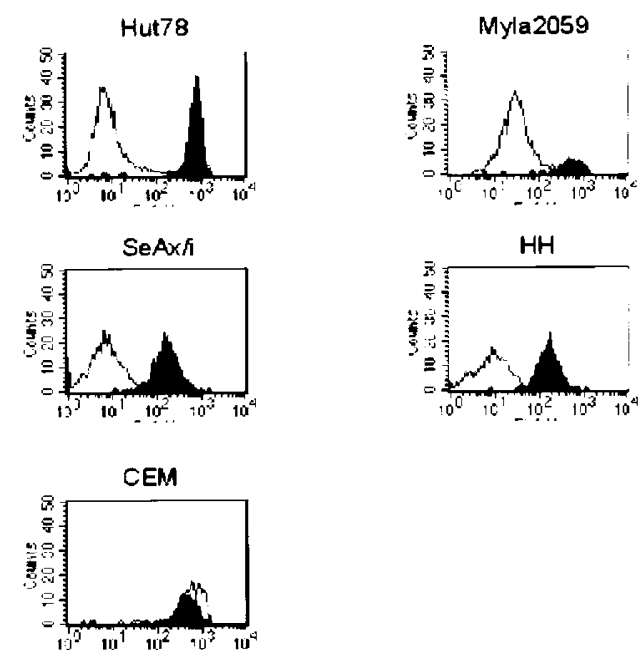

FIGURE 4. Neuraminidase treatment of Sezary cell lines. Neuraminidase treatment exposes PNA-binding sites on Sezary cell lines, demonstrating that Sezary cells have sialylated O-glycans. Cells were treated with $V$. cholerae neuraminidase or buffer control before staining with biotinylated PNA. Increased PNA binding after neuraminidase treatment indicates core 1 O-glycans recognized by PNA are masked by sialic acid on these cells.

Sezary cells in primary skin lesions, indicating that tumor cells synthesize galectin-1. We examined the four Sezary cell lines, HH, SeAx/i, Hut78, and MyLa 2059, for galectin-1 expression by immunoblotting (Fig. 5). Abundant galectin-1 was detected in the $\mathrm{CD}^{-}$cell lines Hut78 and MyLa 2059. However, no galectin-1 was detected in the $\mathrm{CD}^{+}$cell lines $\mathrm{HH}$ and SeAx/i. Thus, in these four cell lines, there was an inverse correlation between galectin-1 synthesis and CD7 expression, suggesting that Sezary cells that lack CD7 can express galectin-1 and survive.

\section{DISCUSSION}

The resistance of Sezary cells to apoptosis presents a major challenge in developing effective

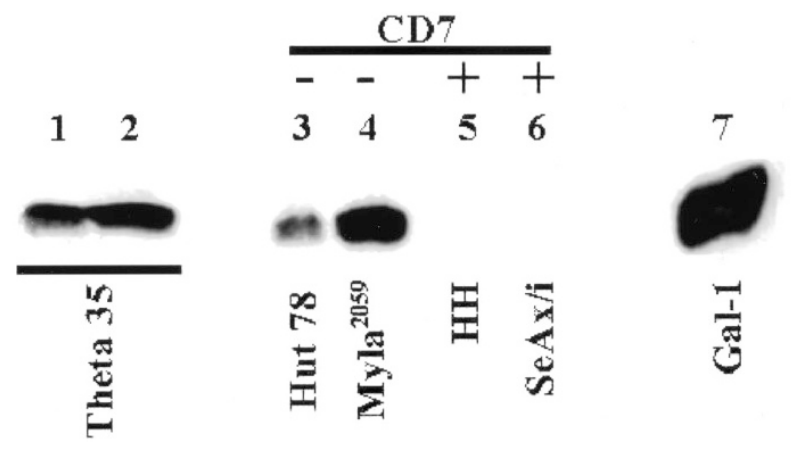

FIGURE 5. Expression of galectin-1 by Sezary cell lines. Immunoblot analysis of total cell lysates of Hut 78 (Lane 3), MyLa 2059 (Lane 4), $\mathrm{HH}$ (Lane 5), and SeAx/i (Lane 6) cell lines (40 $\mu \mathrm{g}$ each). Immunoreactive galectin- 1 is detected in CD7 ${ }^{-}$Hut78 and MyLa 2059 cells, but not in $\mathrm{CD}^{+} \mathrm{HH}$ and SeAx/i cells. As positive controls, total cell lysate of $\theta$-35 cells (40 $\mathrm{g}$, Lane 1; $80 \mu \mathrm{g}$, Lane 2) and purified recombinant galectin-1 (0.5 $\mu \mathrm{g}$, Lane 7$)$ demonstrate immunoreactivity. 
therapies for mycosis fungoides $(1,8)$. In this study, we examined 15 biopsy samples of mycosis fungoides lesions to determine whether Sezary cells are exposed to galectin-1 in the skin. In skin, galectin-1 may have several functions, including participating in cell-cell and cell-matrix adhesion, in addition to inducing T-cell apoptosis. In all samples, abundant extracellular galectin-1 was seen in close contact with Sezary cells and associated small round lymphocytes in the dermis and epidermis. The pattern of galectin-1 expression in vivo indicates that CD7 Sezary cells are exposed to this apoptotic trigger, yet the tumor cells resist galectin-1 cell death.

We have previously demonstrated reversal of galectin-1 resistance in the $\mathrm{CD}^{-}$Sezary cell line Hut78 by expressing CD7 in these cells (36). This implied that all other components of the galectin-1 death pathway besides CD7 were present in Hut78 cells. The present study further analyzed the role of CD7 in galectin- 1 sensitivity using additional Sezary cell lines. The $\mathrm{CD}^{-}$cell lines Hut78 and MyLa 2059 were resistant to galectin-1-induced cell death. Although the $\mathrm{CD}^{+}$cell line $\mathrm{HH}$ was modestly susceptible to galectin-1-induced cell death, another $\mathrm{CD}^{+}$cell line, SeAx/i, was not susceptible to galectin-1. These findings support the hypothesis that the absence of CD7 is one important factor mediating the reduced sensitivity of Sezary cells to apoptosis via galectin-1 (38). However, additional factors, i.e., changes in cell surface glycosylation, may also contribute to Sezary cell resistance to galectin-1 death.

In additions to CD7 expression, galectin-1-induced cell death requires expression of a specific glycosyltransferase by T cells, the core $2 \mathrm{GnT}$ (42). The core $2 \mathrm{GnT}$ creates core $2 \mathrm{O}$-glycans that bear poly-LacNAc sequences preferentially recognized by galectin-1. It is noteworthy that the presence of terminal sialic acid on core $1 \mathrm{O}$-glycans, added by the ST3Gal I sialyltransferase, inhibits the action of the core 2 GnT enzyme (49). Additional glycosyltransferases, such as the GnT V or the ST6Gal I, also regulate the expression or accessibility of saccharide ligands recognized by galectin- $1(42,43,45,46$, 51). Thus, in addition to CD7 expression, regulated expression of appropriate glycosyltransferases can also influence susceptibility to galectin-1.

In mycosis fungoides biopsies, the Sezary cells were $\mathrm{PHA}^{+}, \mathrm{SNA}^{-}$, and $\mathrm{PNA}^{-}$(Fig. 1). This glycosylation phenotype was also observed for the four Sezary cell lines examined. Loss of CD7 expression and aberrant glycosylation, i.e., low PNA binding, could both contribute to decreased galectin-1 sensitivity (39). Increased PNA reactivity after neuraminidase treatment of the cell lines indicated that the cells bear primarily sialylated core $1 \mathrm{O}$-glycans and thus lack the core $2 \mathrm{O}$-glycans required for T-cell susceptibility to galectin-1 (42).
Detection of galectin-1 in macrophages, dendritic cells, and fibroblasts (Fig. 1) is consistent with prior reports $(34,35)$ and indicates that many cell types may secrete galectin-1 in skin. We also observed galectin-1 immunoreactivity within the cytoplasm of $\mathrm{CD}^{-}$Sezary cells in skin lesions (Fig. 1B). This correlated with the abundant galectin-1 expression by the $\mathrm{CD}^{-}$cell lines Hut78 and MyLa 2059 (Fig. 5); thus, $\mathrm{CD}^{-}$Sezary cells can express galectin-1 while escaping cell death. The inverse relationship between galectin-1 expression and galectin-1 sensitivity is similar to that described for other neoplasms, e.g., prostate cancer (22).

What selective advantage would loss of sensitivity to galectin-1 apotosis confer to tumor cells? First, resistance to galectin-1-induced cell death may provide Sezary cells with a survival advantage. Second, production of galectin- 1 by Sezary cells might also contribute to apoptotic elimination of reactive tumor-infiltrating $\mathrm{T}$ cells. A paracrine effect of galectin- 1 released by tumor cells on lymphocytes has previously been proposed (52). Various types of tumors express death ligands, such as Fas, as a mechanism to eradicate tumor-specific T cells (11, 53-55). The expression of galectin- 1 by $\mathrm{CD}^{-}$Sezary cells in skin lesions and by $\mathrm{CD}^{-}$Sezary cell lines suggests that lack of CD7 expression contributes to both apoptosis resistance and immune evasion by tumor cells. Indeed, lack of CD7 on circulating Sezary cells has been associated with a poor prognosis in patients (56).

Our results demonstrate that lack of CD7 expression on Sezary cell lines correlates with reduced susceptibility to galectin-1-induced apoptosis, although CD7 expression was not sufficient to make the $\mathrm{HH}$ and SeAx/I cells susceptible to galectin-1 cell death. Altered glycosylation, specifically the presence of sialylated core 1 O-glycans, may also contribute to the reduced galectin-1 sensitivity of Sezary cells. Identification of specific glycosyltransferase genes that regulate susceptibility to galectin-1 apoptosis may provide novel therapeutic targets to enhance tumor cell death in mycosis fungoides.

Acknowledgments: We thank Dr. Scott Binder for valuable advice and support and Mabel Pang for technical assistance.

\section{REFERENCES}

1. Siegel RS, Pandolfino T, Guitart J, Rosen S, Kuzel TM. Primary cutaneous T-cell lymphoma: review and current concepts. J Clin Oncol 2000;18:2908-25.

2. Willemze R, Kerl H, Sterry W, Berti E, Cerroni L, Chimenti S, et al. EORTC classification for primary cutaneous lymphomas: a proposal from the Cutaneous Lymphoma Study Group of the European Organization for Research and Treatment of Cancer. Blood 1997;90:354-71. 
3. Zackheim HS, Vonderheid EC, Ramsay DL, LeBoit PE, Rothfleisch J, Kashani-Sabet M. Relative frequency of various forms of primary cutaneous lymphomas. J Am Acad Dermatol 2000;43:793-6.

4. Kim YH, Hoppe RT. Mycosis fungoides and the Sezary syndrome. Semin Oncol 1999;26:276-89.

5. Burg G, Dummer R, Dommann S, Nestle F, Nickoloff B. Pathology of cutaneous T-cell lymphoma. Hematol Oncol Clin North Am 1995;9:961-95.

6. Knowles DM. Immunophenotypic and antigen receptor gene rearrangement analysis in T cell neoplasia. Am J Pathol 1989;134:761-85.

7. Kim YH, Chow S, Varghese A, Hoppe RT. Clinical characteristics and long-term outcome of patients with generalized patch and/or plaque (T2) mycosis fungoides. Arch Dermatol 1999;135:26-32.

8. Apisarnthanarax N, Talpur R, Duvic M. Treatment of cutaneous $\mathrm{T}$ cell lymphoma: current status and future directions. Am J Clin Dermatol 2002;3:193-215.

9. Duvic M, Cather JC. Emerging new therapies for cutaneous T-cell lymphoma. Dermatol Clin 2000;18:147-56.

10. Van Haselen CW, Flens MJ, Scheper RJ, van der Valk P, Scheffer GL, Toonstra J, et al. Multidrug resistance related proteins in primary cutaneous lymphomas. Adv Exp Med Biol 1999;457:119-31.

11. Nevala H, Karenko L, Vakeva L, Ranki A. Proapoptotic and antiapoptotic markers in cutaneous T-cell lymphoma skin infiltrates and lymphomatoid papulosis. Br J Dermatol 2001; 145:928-37.

12. Qin JZ, Zhang CL, Kamarashev J, Dummer R, Burg G, Dobbeling $U$. Interleukin-7 and interleukin-15 regulate the expression of the bcl-2 and c-myb genes in cutaneous T-cell lymphoma cells. Blood 2001;98:2778-83.

13. Dobbeling U, Dummer R, Laine E, Potoczna N, Qin JZ, Burg G. Interleukin-15 is an autocrine/paracrine viability factor for cutaneous T-cell lymphoma cells. Blood 1998;92:252-8.

14. Kikuchi A, Nishikawa T. Apoptotic and proliferating cells in cutaneous lymphoproliferative diseases. Arch Dermatol 1997;133:829-33.

15. Rabinovich GA. Galectins: an evolutionarily conserved family of animal lectins with multifunctional properties; a trip from the gene to clinical therapy. Cell Death Differ 1999;6: 711-22.

16. Liu FT. Galectins: a new family of regulators of inflammation. Clin Immunol 2000;97:79-88.

17. Cooper DN, Barondes SH. God must love galectins; he made so many of them. Glycobiology 1999;9:979-84.

18. Perillo NL, Marcus ME, Baum LG. Galectins: versatile modulators of cell adhesion, cell proliferation, and cell death. J Mol Med 1998;76:402-12.

19. Vespa GN, Lewis LA, Kozak KR, Moran M, Nguyen JT, Baum LG, et al. Galectin-1 specifically modulates TCR signals to enhance TCR apoptosis but inhibit IL-2 production and proliferation. J Immunol 1999;162:799-806.

20. Perillo NL, Uittenbogaart CH, Nguyen JT, Baum LG. Galectin-1, an endogenous lectin produced by thymic epithelial cells, induces apoptosis of human thymocytes. J Exp Med 1997;185:1851-8.

21. Perillo NL, Pace KE, Seilhamer JJ, Baum LG. Apoptosis of T cells mediated by galectin-1. Nature 1995;378:736-9.

22. Ellerhorst J, Nguyen T, Cooper DN, Lotan D, Lotan R. Differential expression of endogenous galectin-1 and galectin-3 in human prostate cancer cell lines and effects of overexpressing galectin-1 on cell phenotype. Int J Oncol 1999;14: 217-24.

23. Ellerhorst J, Nguyen T, Cooper DN, Estrov Y, Lotan D, Lotan R. Induction of differentiation and apoptosis in the prostate cancer cell line LNCaP by sodium butyrate and galectin-1. Int J Oncol 1999;14:225-32.
24. Wells V, Davies D, Mallucci L. Cell cycle arrest and induction of apoptosis by beta galactoside binding protein (beta GBP) in human mammary cancer cells. A potential new approach to cancer control. Eur J Cancer 1999;35:978-83.

25. Kuwabara I, Kuwabara Y, Yand R-Y, Schuler M, Green DR, Zuraw BL, et al. Galectin-7 (PIG1) exhibits pro-apoptotic function through JNK activation and mitochondrial cytochrome c release. J Biol Chem 2002;277:3487-97.

26. Berenerd F, Sarasin A, Magnaldo T. Galectin-7 overexpression is associated with the apoptotic process in UVBinduced sunburn keratinocytes. Proc Natl Acad Sci USA 1999;96:11329-34.

27. Moon BK, Lee YJ, Battle P, Jessup JM, Raz A, Kim HR. Galectin-3 protects human breast carcinoma cells against nitric oxide-induced apoptosis: implication of galectin-3 function during metastasis. Am J Pathol 2001;159:1055-60.

28. Matarrese P, Fusco O, Tinari N, Natoli C, Liu FT, Semeraro ML, et al. Galectin-3 overexpression protects from apoptosis by improving cell adhesion properties. Int J Cancer 2000;85: 545-54.

29. Akahani S, Nangia-Makker P, Inohara H, Kim HR, Raz A. Galectin-3: a novel antiapoptotic molecule with a functional BH1 (NWGR) domain of Bcl-2 family. Cancer Res 1997;57: 5272-6.

30. Yang RY, Hsu DK, Liu FT. Expression of galectin-3 modulates T-cell growth and apoptosis. Proc Natl Acad Sci U S A 1996; 93:6737-42.

31. Wollina U, Graefe T, Feldrappe S, Andre S, Wasano K, Kaltner $\mathrm{H}$, et al. Galectin fingerprinting by immuno- and lectin histochemistry in cutaneous lymphoma. J Cancer Res Clin Oncol 2002;128:103-10.

32. Plzak J, Smetana K Jr, Hrdlickova E, Kodet R, Holikova Z, Liu FT, et al. Expression of galectin-3-reactive ligands in squamous cancer and normal epithelial cells as a marker of differentiation. Int J Oncol 2001;19:59-64.

33. Smetana K, Holikova Z, Klubal R, Bovin NV, Dvorankova B, Bartunkova J, et al. Coexpression of binding sites for A(B) histo-blood group trisaccharides with galectin-3 and Lag antigen in human Langerhans cells. J Leukoc Biol 1999;66: $644-9$.

34. Akimoto Y, Hirabayashi J, Kasai K, Hirano H. Expression of the endogenous 14-kDa beta-galactoside-binding lectin galectin in normal human skin. Cell Tissue Res 1995;280:1-10.

35. Allen HJ, Sucato D, Gottstine S, Kisailus E, Nava H, Petrelli N, et al. Localization of endogenous beta-galactoside-binding lectin in human cells and tissues. Tumour Biol 1995;12:5260.

36. Pace KE, Hahn HP, Pang M, Nguyen JT, Baum LG. Cutting edge. CD7 delivers a pro-apoptotic signal during galectin-1induced T cell death. J Immunol 2000;165:2331-4.

37. Pace KE, Lee C, Stewart PL, Baum LG. Restricted receptor segregation into membrane microdomains occurs on human T cells during apoptosis induced by galectin-1. J Immunol 1999;163:3801-11.

38. Rappl G, Abken H, Muche JM, Sterry W, Tilgen W, Andre S, et al. $\mathrm{CD} 4+\mathrm{CD} 7$ - leukemic T cells from patients with Sezary syndrome are protected from galectin-1-triggered $\mathrm{T}$ cell death. Leukemia 2002;16:840-5.

39. Hakomori S. Glycosylation defining cancer malignancy: new wine in an old bottle. Proc Natl Acad Sci U S A 2002;99: 10231-3.

40. Baum LG, Pang M, Perillo NL, Wu T, Delegeane A, Uittenbogaart $\mathrm{CH}$, et al. Human thymic epithelial cells express an endogenous lectin, galectin-1, which binds to core 2 O-glycans on thymocytes and T lymphoblastoid cells. J Exp Med 1995;181:877-87.

41. Gillespie W, Paulson JC, Kelm S, Pang M, Baum LG. Regulation of alpha 2,3-sialyltransferase expression correlates with conver- 
sion of peanut agglutinin (PNA) + to PNA- phenotype in developing thymocytes. J Biol Chem 1993;268:3801-4.

42. Galvan M, Tsuboi S, Fukuda M, Baum LG. Expression of a specific glycosyltransferase enzyme regulates $\mathrm{T}$ cell death mediated by galectin-1. J Biol Chem 2000;275:16730-7.

43. Galvan M, Evans DP, Pace KE, Nguyen JT, Baum LG. Glycosylation controls $\mathrm{T}$ cell death induced by galectin-1 [abstract]. Glycobiology 2000;10:1087.

44. Brinck U, Korabiowska M, Bosbach R, Gabius HJ. Detection of inflammation- and neoplasia-associated alterations in human large intestine using plant/invertebrate lectins, galectin-1 and neoglycoproteins. Acta Anat 1998;161:219-33.

45. Baum LG, Derbin K, Perillo NL, Wu T, Pang M, Uittenbogaart C. Characterization of terminal sialic acid linkages on human thymocytes: correlation between lectin-binding phenotype and sialyltransferase expression. J Biol Chem 1996;271: 10793-9.

46. Demetriou M, Granovsky M, Quaggin S, Dennis JW. Negative regulation of T-cell activation and autoimmunity by Mgat5 $N$-glycosylation. Nature 2001;409:733-9.

47. Braut-Boucher F, Font J, Pichon J, Paulin Y, Boukhelifa M, Aubery M, et al. T lymphocytes from Sezary syndrome patients express betal integrins whose beta(1-6)-branched $N$-linked oligosaccharides reflect their adhesive capacity. Leuk Res 1998;22:947-52.

48. Derappe C, Haentjens G, Lemaire S, Feugeas JP, Lebbe C, Pasqualetto $\mathrm{V}$, et al. Circulating malignant lymphocytes from Sezary syndrome express high level of glycoproteins carrying beta (1-6) $N$-acetylglucosamine-branched $N$-linked oligosaccharides. Leukemia 1996;10:138-41.

49. Priatel JJ, Chui D, Hiraoka N, Simmons CJT, Richardson KB, Page DM, et al. The ST3Gal-I sialyltransferase controls CD8+
T lymphocyte homeostasis by modulating O-glycan biosynthesis. Immunity 2000;12:273-83.

50. Galvan M, Murali-Krishna K, Ming LL, Baum L, Ahmed R. Alterations in cell surface carbohydrates on $\mathrm{T}$ cells from virally infected mice can distinguish effector/memory CD8+ T cells from naive cells. J Immunol 1998;161:641-8.

51. Di Virgilio S, Glushka J, Moremen K, Pierce M. Enzymatic synthesis of natural and $13 \mathrm{C}$ enriched linear poly- $N$ acetyllactosamines as ligands for galectin-1. Glycobiology 1999;9:353-64.

52. Salvatore P, Benvenuto G, Pero R, Lembo F, Bruni CB, Chiariotti L. Galectin-1 gene expression and methylation state in human T leukemia cell lines. Int J Oncol 2000;17: 1015-8.

53. Ni X, Hazarika P, Zhang C, Talpur R, Duvic M. Fas ligand expression by neoplastic $\mathrm{T}$ lymphocytes mediates elimination of CD8 + cytotoxic T lymphocytes in mycosis fungoides: a potential mechanism of tumor immune escape? Clin Cancer Res 2001;7:2682-92.

54. Zietz C, Rumpler U, Sturzl M, Lohrs U. Inverse relation of Fas-ligand and tumor-infiltrating lymphocytes in angiosarcoma: indications of apoptotic tumor counterattack. Am J Pathol 2001;159:963-70.

55. O'Connell J, Bennett MW, O’Sullivan GC, Collins JK, Shanahan F. Resistance to Fas (APO-1/CD95)-mediated apoptosis and expression of Fas ligand in esophageal cancer: the Fas counterattack. Dis Esophagus 1999;12:83-9.

56. Bernengo MG, Quaglino P, Novelli M, Cappello N, Doveil GC, Lisa F, et al. Prognostic factors in Sezary syndrome: a multivariate analysis of clinical, haematological and immunological features. Ann Oncol 1998;9:857-63. 